\title{
Aminonitrile Potential in Terms of Pharmacological and Clinical Applicability
}

Hélida Maravilha Dantas e Sousa Almeida (helidacaico@ hotmail.com) ${ }^{a}$, Igor de Sousa Oliveira (igordesousao1@gmail.com ) ${ }^{a}$,Sávio Benvindo Ferreira (savio.benvindo@professor.ufcg.edu.br $)^{b}$.

${ }^{a}$ Graduate Student, Center for Teacher Training (CFP), Federal University of Campina Grande (UFCG), Cajazeiras campus, Paraíba, Brazil.

${ }^{b}$ Professor of Science of Life Academic Unit, Center for Teacher Training (CFP), Federal University of Campina Grande (UFCG), Cajazeiras campus, Paraíba, Brazil

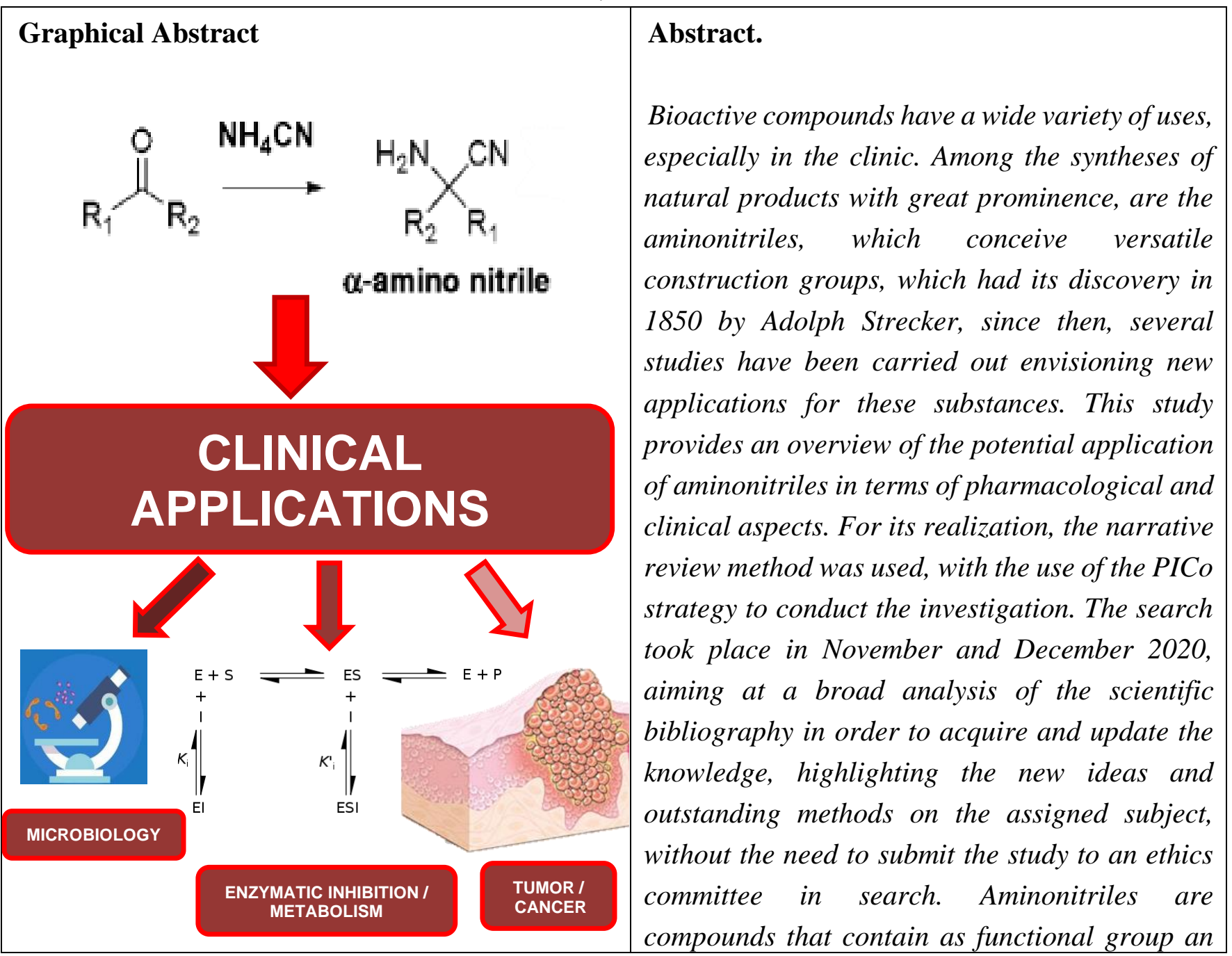


amino (NH2) and a nitrile $(\mathrm{CN})$, they have several reactivity modes, among them hydrolysis, $\alpha$-deprotonation, quarternization, reductive decay, nitrile reduction and retro reaction Strecker. The studies reveal a great emphasis on the microbiological and anticancer potential, protagonism in the inhibition of proteases such as cathepsin $C$, and in the synthesis of natural products, such as alkaloids.

Thus, there is still a need for investigative research that explores the antibacterial and viral potential, as well as clinical studies that provide greater evidence of the potential of these agents and their derivatives against tumors.

\section{Introduction}

Bioactive compounds have a wide variety of uses, especially in the clinic. They are organic molecules that can be obtained from plant, animal, or synthetic sources, being mostly heterocyclic. Its main feature is the presence of a ring containing an element other than carbon. When these substances have a high metabolic stability, resistance to hydrolysis, as well as promising pharmacokinetic and pharmacodynamic results, they are indicated for the development of drugs (1).

Amidst syntheses of natural products with great prominence, they are as aminonitriles, that conceive versatile and precious construction groups in the synthesis of synthetic compounds. Its discovery occurred in 1850 by the German chemist Adolph Strecker, who from its hydrolysis determined the synthesis of amino acids (2). Strecker developed cinamide $\left(\mathrm{H}_{2} \mathrm{NCN}\right)$ as a condensation between amines, carbonyl compounds and hydrocyanic acid (3).

Since then, a series of studies have been carried out over the years to understand new applications for these substances, which has made possible new methods for synthetic drugs and natural products. In this context, this study provides an overview of the potential for the application of aminonitriles in relation to pharmacological and clinical aspects; thus, its scope is to carry out a narrative review of the field of study, identifying and analyzing the scientific literature, thus providing a foundation for scholars in the development of future research, subsidizing from basic investigations to clinical conduct.

\section{Materials and Methods}

This study is configured with a qualitative, exploratory descriptive, theoretical approach. The narrative review method was used to conceive a pertinent discussion of the state of the art of the topic. For this, a wide analysis of the scientific bibliography is carried out in order to acquire and update the knowledge, emphasizing the new ideas and methods highlighted in the selected literature. Initially, a guiding question was developed to conduct the investigation, using the PICo strategy, with P for population, I for interest and Co corresponding to the context.

Thus, the following question was asked "what is the general picture $(\mathrm{Co})$ of aminonitriles $(\mathrm{P})$ regarding biative potential (pharmacological and clinical) (I)?" From this, the search of the scientific 
bibliography began, which occurred during the months of November and December 2020, in the databases destined to index journals and scientific articles. The terms used to carry out the search were, in a combined way, aminonitriles; bioactivity, without delimiting a time interval. Works were selected that portrayed in their abstract or title, explicitly, that the text relates to the potential and activities of aminonitriles in relation to biological applications.

Priority was given to works published in the form of scientific articles. The search took place in Portuguese, English and Spanish. The excluded articles did not meet the established inclusion criteria and / or were duplicated. After this stage, the selected works were read, highlighting the main contributions of aminonitriles in the context of biological applications.

This analysis took place individually for each work studied, and only then the state of the art was built, aiming to answer the guiding question initially carried out, thus contemplating the purpose of this review. It was not necessary to resort to judges to carry out a qualitative treatment of the extracted data, just as it was not necessary to submit the study to a research ethics committee, since the samples were obtained from public data.

\section{Results and Discussion}

Aminonitriles are compounds that contain as functional group an amino $\left(\mathrm{NH}_{2}\right)$ and a nitrile $(\mathrm{CN})$. A-aminonitriles can be converted into amino acids when hydrolyzed, generating the reaction intermediate to $\alpha$-aminoamide (4). This compound has a greater tendency to donate electrons, that is, it has high reactivity and attractiveness, which is why they are multiform and widely useful in the synthesis of natural products for various applications. Among the modes of reactivity of aminonitriles, in addition to hydrolysis, $\alpha$-deprotonation, quarternization (protonation for cation formation), reductive decay (in the nitrile group), nitrile reduction and the retro-Strecker reaction (5).

This multiplicity and high attractiveness provide a great diversity in pharmacological applications and, consequently, a new prospect for clinical purposes. Several studies demonstrate the antifungal activity of aminonitriles, and among the strains of fungi studied, the one with the greatest sensitivity to the substances applied was Candida albicans (6-8), however, promising results are also observed against strains of Candida tropicalis (6) and Cryptococcus neoformans (7). Still with regard to microbiological activity, aminonitriles have promising antimicrobial activity against pathogenic bacteria Staphylococcus aureus, Escherichia coli, Salmonella typhi, in addition to antitubercular activity with low cytotoxicity against Mycobacterium tuberculosis H37Rv (8).

In addition to microbiological application, in vitro antitumor activity has been reported. One study evaluated the cytostatic activity of two aminonitrile compounds against 60 tumor cell lines, which are present in leukemia, melanoma, lung, colon, brain, breast, ovary, kidney and prostate. A remarkable activity was revealed against 39 human tumor cell lines of one of the studied compounds and the second substance showed activity against 41 types of cancer cells. The most sensitive strains were leukemia, colon, and breast cancer (7).

Another prominent function pertaining to aminonitriles is their performance as potential protease inhibitors (9). Here, there is an irreversible hydrolysis of a peptide bond by a nucleophilic attack to an amino acid, consecutively, hydrolysis of a tetrahedral intermediate (10). Thus, aminonitriles act as mimetic agents of protein amino acids in various metabolisms and can be applied in various biological contexts. An example of this are anti-hyperglycemic drugs such as vildagliptin, which act by inhibiting 
the enzyme dipeptidyl peptidase 4 (DDP-4) with a covalent bond in the amino acid serine, which acts by inactivating incretins (11). In this case, there is a regulation of the peptide hormone similar to glucagon 1 (GLP-1), increasing its time of action on glucose metabolism (12).

Still in the context of this mechanism of action, aminonitriles are cysteine protease inhibitors (13). Acetamidoacetonitrile, a type of $\alpha$-aminonitrile, served as the basis for the development of a cathepsin K inhibitor, Odanacatib, which was selected for clinical studies in cases of osteoporosis, treatment of postmenopausal osteoporosis and bone metastasis (14-15). Cathepsin C, also called dipeptidyl peptidase I (DPP-I), is a very attractive target for researchers who see its inhibition, since this enzyme plays a leading role in the inflammatory process, serving as a therapeutic target (16). Studies involving in vitro and in vivo $\alpha$-aminonitrile derivatives have demonstrated an inhibitory power of more than $90 \%$, in addition to having good metabolic stability $(17 ; 9)$.

Another highlight regarding the therapeutic potential of aminonitriles is the ability to inhibit sphingomyelin synthetase $(18 ; 9)$, which can serve as a therapeutic potential for metabolic diseases, since the imbalance in sphingomyelin biosynthesis is linked to the genesis of several serious chronic diseases, such as diabetes, atherosclerosis, and cancer.

Aminonitriles can also act as a reagent for the synthesis of pyrazinones, which are heterocyclic compounds that act especially as inhibitors of serine proteases, being widely studied as to their biological potential (19). The genesis of indole alkaloids can be affected from these substances, having an immense importance in clinical application, such as reserpine, which can act as antihypertensive drugs (20-21). Still regarding polycyclic indole molecules, studies show that they still have a moderate capacity for cytotoxicity and to inhibit enzymes that act in the metabolism of tumor cells (22).

\section{Conclusions}

Aminonitriles are heterocyclic biochemical substances that have a multitude of pharmacological and clinical applications. The studies carried out reveal a wide multiplicity of discoveries and bioactive functionalities that aminonitriles have, with an emphasis on microbiological activity, with a focus on antifungal capacity, anticancer activity and, especially, as protease inhibitors. This occurs due to the mimetic capacity of these substances and their high attractiveness, which trigger a nucleophilic attack on an amino acid that causes proteolysis.

The results found propose a series of new possibilities of synthesis and clinical functionalities of aminonitriles, as the inhibiting activity of the DPP-I enzyme may indicate a promising activity against cruzipain, which has a high structural similarity, and is responsible for the pathogenicity of Trypanosoma cruzi. In addition, the production of natural products and compounds with high pharmacological and therapeutic potential.

However, there is a need for further investigation of the antibacterial and antiviral potential, as well as the capacity against parasites responsible for neglected diseases, such as Chagas' disease. In addition, further clinical studies are needed to provide greater evidence of the potential of these agents and their derivatives against tumors.

\section{References}

1. Lopes Paulo Guilherme Markus, Spader Tatiana, Alves Sydney Hartz, Dornelles Luciano. PERSPECTIVAS SOBRE ATIVIDADES ANTIMICROBIANAS DE COMPOSTOS 
DERIVADOS 1,2,4-OXADIAZÓLICOS. Saúde (Santa Maria) [Internet]. 2005 [cited 2020 Dec 30];31:57 - 58. Available from: https://periodicos.ufsm.br/revistasaude/article/view/6410/3892

2. Strecker, A. (1850), Ueber die künstliche Bildung der Milchsäure und einen neuen, dem Glycocoll homologen Körper;. Justus Liebigs Ann. Chem., 75: 27-45. https://doi.org/10.1002/jlac.18500750103

3. Cleaves H.J. (2011) Cyanamide. In: Gargaud M. et al. (eds) Encyclopedia of Astrobiology. Springer, Berlin, Heidelberg. https://doi.org/10.1007/978-3-642-11274-4_375

4. Cleaves H.J. (2011) Aminonitrile. In: Gargaud M. et al. (eds) Encyclopedia of Astrobiology. Springer, Berlin, Heidelberg. https://doi.org/10.1007/978-3-642-11274-4_66

5. Grundke Caroline, Vierengel Nina, Opatz Till. $\alpha$-Aminonitriles: From Sustainable Preparation to Applications in Natural Product Synthesis. The Chemical Record [Internet]. 2020 [cited 2020 Dec 30];20:989. Available from: https://doi.org/10.1002/tcr.202000066

6. Collin X, Sauleau A, Coulon J. 1,2,4-Triazolo mercapto and aminonitriles as potent antifungal agents. Bioorg Med Chem Lett. 2003 Aug 4;13(15):2601-5. doi: 10.1016/s0960-894x(03)00378-0. PMID: 12852975.

7. Acosta, Paola et al. "Microwave-Assisted Synthesis of Novel Pyrazolo[3,4-g][1,8]naphthyridin-5amine with Potential Antifungal and Antitumor Activity." Molecules (Basel, Switzerland) vol. 20,5 8499-520. 12 May. 2015, doi:10.3390/molecules20058499

8. Shaikh IN, Hosamani KM, Kurjogi MM. Design, synthesis, and evaluation of new $\alpha$-aminonitrilebased benzimidazole biomolecules as potent antimicrobial and antitubercular agents. Arch Pharm (Weinheim). 2018 Feb;351(2). doi: 10.1002/ardp.201700205. Epub 2018 Jan 22. PMID: 29356105.

9. Kouznetsov VV, Galvis CEP, Strecker reaction and $\alpha$-amino nitriles: Recent advances in their chemistry, synthesis, and biological properties, Tetrahedron (2018), doi: 10.1016/ j.tet.2018.01.005

10. Lecaille F, Kaleta J, Brömme D. Human and parasitic papain-like cysteine proteases: their role in physiology and pathology and recent developments in inhibitor design. Chem Rev. 2002 Dec;102(12):4459-88. doi: 10.1021/cr0101656. PMID: 12475197.

11. Mulakayala N, Reddy CHU, Iqbal J, Pal M (2010) Synthesis of dipeptidyl peptidase-4 inhibitors: a brief overview. Tetrahedron 66:4919-4938

12. Scheen AJ. Pharmacokinetics of dipeptidylpeptidase-4 inhibitors. Diabetes Obes Metab. 2010 Aug;12(8):648-58. doi: 10.1111/j.1463-1326.2010.01212.x. PMID: 20590741.

13. Turk V., Stoka V., Vasiljeva O., Renko M., Sun T., Turk B., Turk D. Cysteine cathepsins: From structure, function and regulation to new frontiers. Biochim. Biophys. Acta. 2012;1824:68-88. doi: 10.1016/j.bbapap.2011.10.002

14. Wijkmans J, Gossen J. Inhibitors of cathepsin K: a patent review (2004 - 2010). Expert Opin Ther Pat. 2011 Oct;21(10):1611-29. doi: 10.1517/13543776.2011.616283. PMID: 21923554.

15. McClung Michael R, et al. Odanacatib for the treatment of postmenopausal osteoporosis: results of the LOFT multicentre, randomised, double-blind, placebo-controlled trial and LOFT Extension study. The Lancet [Internet]. 2019 [cited 2021 Jan 3];7:899-911. Available from: https://doi.org/10.1016/S2213-8587(19)30346-8

16. Korkmaz, Brice \& Lesner, Adam \& Guarino, Carla \& Wysocka, Magdalena \& Kellenberger, Christine \& Watier, Hervé \& Specks, Ulrich \& Gauthier, Francis \& Jenne, Dieter. (2016). Inhibitors and Antibody Fragments as Potential Anti-Inflammatory Therapeutics Targeting Neutrophil Proteinase 3 in Human Disease. Pharmaceutical Reviews. 68. 603-630. 10.1124/pr.115.012104.

17. Anderskewitz, R.; Grauert, M.; Grundl, M.; Oost, T.; Pautsch, A.; Peters, S. U.S. Patent No. 9,073,869, 2015. Washington, DC: U.S. Patent and Trademark Office. 
18. Deng X, Lin F, Zhang Y, Li Y, Zhou L, et al. (2014) Identification of small molecule sphingomyelin synthase inhibitors. Eur J Med Chem 73: 1-7.

19. Gising, J., Örtqvist, P., Sandström, A., Larhed, M. A straightforward microwave method for rapid synthesis of N-1, C-6 functionalized 3,5-dichloro-2(1H)-pyrazinones. Org. Biomol. Chem., 2009, 7, 2809-2815. Also highlighted in Synfacts, 2009, 9, 966.

20. Stork G. The stereospecific synthesis of reserpine. Pure Appl Chem. 1989;61:439-442

21. Orejarena Pacheco, J. C., Lipp A., Nauth A. M., Acke F., Dietz J.-P., Opatz T., A Highly Active System for the Metal-Free Aerobic Photocyanation of Tertiary Amines with Visible Light: Application to the Synthesis of Tetraponerines and Crispine A Chem. Eur. J. 2016, 22, 5409

22. Ventosa-Andrés P, González-Vera JA, Valdivielso AM, Teresa García-López M, Herranz R. Synthesis and antitumoral evaluation of indole alkaloid analogues containing an hexahydropyrrolo[1',2',3':1,9a,9]imidazo[1,2-a]indole skeleton. Bioorg Med Chem. 2008 Oct 15;16(20):9313-22. doi: 10.1016/j.bmc.2008.08.070. Epub 2008 Aug 31. PMID: 18818089. 